\title{
A case of an 81-year-old woman with 'broken-heart syndrome' after a house fire
}

\author{
Teryn Perkins BS, Kenneth Iwuji MD, Phumpattra Chariyawong MD, Leigh Ann Jenkins MD
}

\begin{abstract}
Takotsubo cardiomyopathy is a transient cardiomyopathy predominantly characterized by left ventricular hypokinesis and wall motion abnormalities, usually apical ballooning during the systolic phase of heart contraction. The clinical presentation may closely mimic acute coronary syndrome. The majority of the cases are diagnosed in post-menopausal Caucasian women. The exact mechanism of takotsubo cardiomyopathy is unknown. To avoid complications and mortality, early diagnosis and treatment are important.
\end{abstract}

Keywords: Takotsubo cardiomyopathy, broken heart syndrome, ventriculogram, acute coronary syndrome, myocardial infarction

\section{INTRODUCTION}

Heart disease is the leading cause of death among all women in the United States, regardless of ethnicity. ${ }^{1}$ Takotsubo cardiomyopathy, commonly known as "broken-heart syndrome," is a transient cardiomyopathy predominantly characterized by left ventricular hypokinesis and wall motion abnormalities; ventriculograms usually demonstrate apical ballooning during the systolic phase of heart contraction. Takotsubo cardiomyopathy is a diagnosis of exclusion, believed to be induced by a stressor in the patient's life, whether physical or emotional. It most commonly occurs after intense, often unexpected emotional or physical stress. Women comprise the majority of the disease population. ${ }^{2-5,7,9-10}$ Significant negative emotional stressors, such as those causing grief and shock, have been identified as triggers most often. Physical stressors such as infection and surgery explain why

Corresponding author: Kenneth Iwuji Contact Information: Kenneth.Iwuji@ttuhsc.edu DOI: $10.12746 /$ swrccc.v5i20.404 takotsubo cardiomyopathy is commonly seen in the critical care setting. ${ }^{7}$ It may even develop in patients who have no identifiable trigger. Overall, patients typically have few risk factors for cardiovascular disease, but often have comorbidities, such as chronic obstructive pulmonary disease, affective disorders, and migraine disorders. ${ }^{10}$

There are also cases of takotsubo syndrome triggered by positive, pleasant emotional events, with the study authors dubbing these occurrences as "happy-heart syndrome." Although the development of takotsubo cardiomyopathy is predominantly associated with adverse events, this study demonstrates that a variety of emotional events can contribute to its development. ${ }^{4}$ This suggests an interlinked pathway between cognitive, emotional, and physical stimuli which trigger a sympathetic central nervous system response, ultimately affecting the function of the cardiovascular system. ${ }^{3-4,7,11}$

\section{CASE}

An 81-year-old woman presented to the emergency department with new onset left-sided chest 

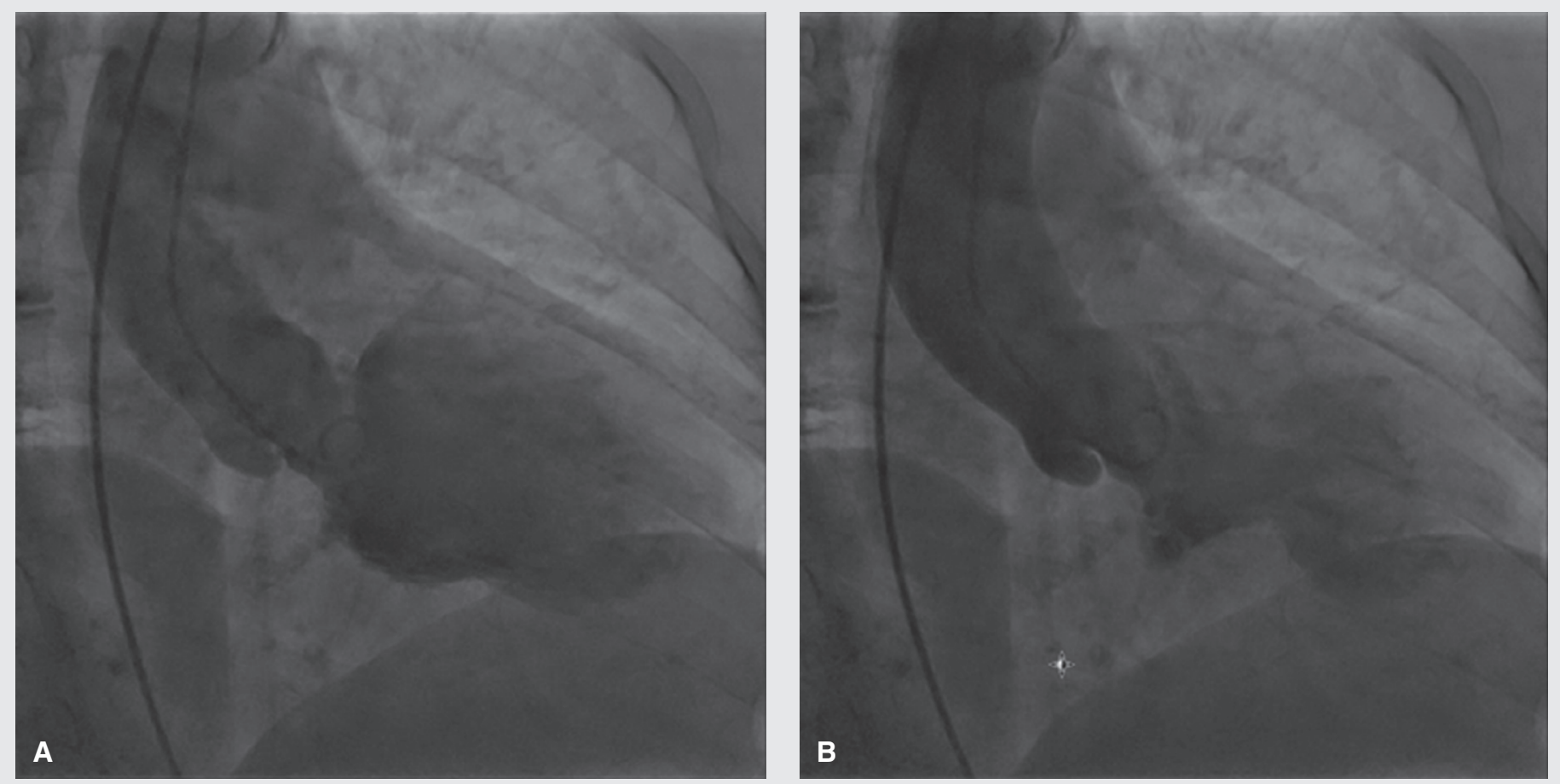

Figure. Left ventricle during diastole (A) and systole (B) with apical ballooning.

tightness associated with nausea and vomiting. The chest pain radiated to her left arm and jaw. Her chest $x$-ray was within normal limits. The electrocardiogram exhibited sinus tachycardia with intermittent premature ventricular complexes, but no significant ST or $\mathrm{T}$ wave abnormalities. Complete blood counts were normal. A complete metabolic panel (including lipase and thyroid stimulating hormone) was normal. Her serum troponin T level $(0.21 \mathrm{ng} / \mathrm{ml})$ was elevated.

Her past medical history was significant for hypertension, asthma, and hypothyroidism. Due to persistent chest pain unrelieved by morphine, aspirin, and sublingual nitroglycerin, she underwent coronary angiography. No significant coronary stenosis or calcification was noted during the angiography. The ventriculogram revealed a hypokinetic left ventricle with apical ballooning (Figure). A transthoracic echocardiography revealed a normal ejection fraction at $50-54 \%$. She was diagnosed with takotsubo cardiomyopathy with normal ejection fraction. After the procedure, we learned that the patient had been under a tremendous amount of stress due to her home burning down in a fire one week prior to presentation. She did not return to clinic for follow-up.

\section{Discussion}

The exact mechanism of takotsubo cardiomyopathy is unknown, but it is hypothesized to be due to excessive sympathetic activation associated with hormonal imbalances. Excess catecholamines produced during times of stress can increase intracellular calcium, which leads to impaired cardiac function through B1 adrenergic stimulation. This calcium overload, in combination with oxidative stress directly induced by catecholamines, has a toxic effect on cardiomyocytes leading to cell death. ${ }^{6}$ The predilection for apical involvement is thought to be due to a higher density of adrenoceptors in the apex as compared to other regions of the heart. ${ }^{9}$

Estrogen may have a role in the pathophysiology. Ninety percent $(90 \%)$ of cases are diagnosed 
in postmenopausal women, with the majority being Caucasian women. ${ }^{2-5,7,9-10}$ In animal studies, estrogen has been shown to impair sympathetic activity. Thus, decreased estrogen levels in postmenopausal women may contribute to the sympathetic overactivation in takotsubo cardiomyopathy. ${ }^{10}$

\section{Clinical Presentation}

This syndrome most commonly presents with chest pain and dyspnea. Subsequent electrocardiogram may reveal acute changes such as ST-segment elevation or T-wave inversions; and cardiac biomarkers may be mildly elevated. ${ }^{9-10}$ These signs and symptoms easily blur the clinical picture and distinction between takotsubo cardiomyopathy and acute coronary syndrome. However, coronary angiography clarifies the true diagnosis of takotsubo syndrome by revealing unobstructed coronary arteries in the presence of apical wall motion abnormalities.

\section{TREATMENT}

While there is no consensus on a specific treatment regimen, beta blockers are the most common treatment, since these drugs limit the adrenergic stimulation from catecholamines. ${ }^{9}$ Angiotensin-converting enzyme inhibitors (ACEi) and angiotensin receptor blockers (ARB) have also been used. A retrospective study of The International Takotsubo Registry reported improved survival after 1 year follow up with the use of ACEi and ARBs. ${ }^{3}$

\section{Prognosis}

Takotsubo cardiomyopathy is completely reversible, and cardiovascular function often returns to normal within 3-4 weeks. ${ }^{9}$ Affected patients remain at risk for recurrence, even years after the initial event has resolved. ${ }^{2,7,9}$ Complications are rare but may include heart failure, cardiogenic shock if systolic function is significantly impaired, arrhythmias, and even death. ${ }^{3,7}$ Men who are affected have a four-fold increased risk of mortality compared to women. This is likely due to the fact that men have complications more frequently than women. ${ }^{5,7}$

\section{Conclusion}

Takotsubo syndrome is an acute, but reversible cardiomyopathy characterized by left ventricular hypokinesis and apical wall motion abnormalities. The clinical presentation can closely mimic acute coronary syndrome. Although full recovery from takotsubo cardiomyopathy is the usual course, fatal complications can occur. It is important to have a good doctorpatient dialogue to gather a complete history that may reveal an underlying exposure or trigger that may have otherwise been overlooked or misattributed as non-contributory to the patient's presentation. Patients involved in fires and other building disasters may be at risk for this syndrome.

Article citation: Perkins T, Iwuji K, Chariyawong P, Jenkins LA. A case of an 81-year-old woman with 'broken-heart syndrome' after a house fire. The Southwest Respiratory and Critical Care Chronicles 2017:5(20):54-57.

From: Department of Internal Medicine at Texas Tech University Health Sciences Center, Lubbock, Texas Submitted: $3 / 17 / 2017$

Accepted: 6/7/2017

Reviewer: Scott Shurmur MD, Aliakbar Arvandi MD Conflicts of interest: none

\section{REFERENCES}

1. Leading Causes of Death in Females, 2014. Centers for Disease Control and Prevention. https://www.cdc.gov/women/ lcod/2014/index.htm. Published January 13, 2017. Accessed February 6, 2017.

2. Garcia M, Mulvagh SL, Bairey Merz CN, Buring JE, Manson JE. Cardiovascular disease in women. Circulation Research 2016, 118(8):1273-1293. doi:10.1161/ CIRCRESAHA.116.307547.

3. Ghadri JR, Cammann VL, Templin C. The International Takotsubo Registry. Heart Failure Clinics, 2016; 12(4):597603. doi:10.1016/j.hfc.2016.06.010.

4. Ghadri JR, Sarcon A, Diekmann J, et al. Happy heart syndrome: role of positive emotional stress in takotsubo syndrome. European Heart Journal 2016, 37(37):2823-2829. doi:10.1093/eurheartj/ehv757.ure 
5. Khera R, Light-McGroary K, Zahr F, Horwitz PA, Girotra $\mathrm{S}$. Trends in hospitalization for takotsubo cardiomyopathy in the United States. American Heart Journal 2016; 172:53-63. doi:10.1016/j.ahj.2015.10.022.

6. Liaudet L, Calderari B, Pacher P. Pathophysiological mechanisms of catecholamine and cocaine-mediated cardiotoxicity. Heart Failure Reviews, 2014; 19(6):815-824. doi:10.1007/ s10741-014-9418-y.

7. Lyon AR, Bossone E, Schneider B, et al. Current state of knowledge on Takotsubo syndrome: a Position Statement from the Taskforce on Takotsubo Syndrome of the Heart Failure Association of the European Society of Cardiology. European Journal of Heart Failure, 2016; 18(1):8-27. doi:10.1002/ejhf.424.
8. Potu KC, Raizada A, Gedela M, Stys A. Takotsubo cardiomyopathy (broken-heart syndrome): a short review. South Dakota Medicine: The Journal of the South Dakota State Medical Assocation, 2016; 69(4):169-171. http://www.ncbi. nlm.nih.gov/pubmed/27263165. Accessed February 6, 2017.

9. Roshanzamir S, Showkathali R. Takotsubo cardiomyopathy a short review. Current Cardiology Reviews, 2013; 9(3):191196. doi:10.2174/1573403x11309030003.

10. Tornvall P, Collste O, Ehrenborg E, Järnbert-Petterson H. A case-control study of risk markers and mortality in takotsubo stress cardiomyopathy. Journal of the American College of Cardiology, 2016; 67(16).

11. Laugharne J, Van de Watt G, Aleksander J. After the fire: the mental health consequences of fire disasters: Erratum. Current Opinion in Psychiatry, 2011; 179 (24). 